Yten que la madera que fuera menester para fazer las obras susodbas el dho monasterio sea obligado a se la dar a los dhos maestros puesta en esta cibdad donde la obieren de labrar e fecha la dba obra el dho monasterio la faga lleuar a su costa de casa de los dhos maestros al dho monasterio.

Yten que lo que tocare a albañileria para fazer sentar la dba obra la faga fazer el dho monasterio a su costa e todas las dhas obras de talla las an de fazer los dhos maestros por sus propias manos e personas sin lo cometer a otra ninguna persona e que demas de la dba madera el dho monasterio les a de dar toda la clavazon y materiales que fuera meneester que los dhos maestros no an de poner y fazer mas trabaxo de las manos lo qual an de empeszar a fazer desde oi en adelante que lo an de darr fecho e acabado dentro de un año siguiente que corre desde oi el dho dia asentado todo e fecho a perfescion a contento del dho monasterio e monges del, e por las manos e trabajo de todo ello les a de pagar el dho monasterio y el dho don baltasar de avila se obligo que les dara e pagara a los dhos maestros quinientos e cinquenta ducados de oro de a tres cientor e sesenta e cinco maravedis qada uno los quales dho don baltasar quedo que les serán dados e pagados treynta ducados en qada una bez en dho año e que les fara la primera paga primero dia del mes de marzo primero que viene deste presente año de la fecha desta carta e asnsi dende en adelante al principo de qada mes los otros treynta ducados e lo que restare de lo susodho en el dho tienpo le a de pagar el dho monasterio a los susodho maestros acabada la dba obra e que si acabada la dba obra el dho monasterio no quedare satis fecho de la dha obra o de alguna parte della que el dho monasterio nombre dos oficiales de dho oficio de qualquier parte que el diho monasterio quisiere los quales a costa de anbas partes y bajo de iuramento vean la dha obra e si declararen que las manos e trabaxo de dha obra no merescen los dhos quinientos e cinquenta ducados que lo que menos declararen que meresca se les defalque del dho prescio e si lo tuvieren rescibido restituyan los dhos maestros al dho monasterio luego e si declararen que merescia mas de los dhos quinientos e cinquenta ducados que el dho monasterio sea obligado e dho don baltasar a les pagar la demasia e que asimiesmo los dhos oficiales bean si la dba obra tiene alguna cosa mal fecha que lo siguren estar mal fecho los dhos maestros la fagan de buena obra e a su costa como los dhos oficiales lo declararen e demas del prescio susodho les a de dar el dho monasterio para ayuda de costa un cahiz de trigo e dos arrouas de azeite luego que los susodhos quiscieren ser pagados dello e desta manera los dhos maestros debajo de la dha mancomunidad en su nombre se obligan el dho don baltasar de avila se obliga en nonbre del dho monasterio e anbas partes se obligaron pagar por esta escriptura de concierto e no se salir ninguno afuera e los dhos maestros de non dexar de facer la dha obra y no leuantar la mano della y asta lo acabar e si no lo fizieren que el dho monesterio a costa de dhos maestros faga facer y acabar la dha obra...

...e en testimonio dello otorgaron la presente ante mi el dho escribano $\mathrm{p}^{\circ}$ e testigos y uso escritos en la dha cibdad de Xerez de la frontera en la casa bodega del dho monasterio en el dho dia mes i año susodho e los dhos otorgantes lo firmaron de sus nonbres en el registro testigos que fueron presentes el bachiller antonio de Cuenca, anton garcia Copin escribano de Xerez e francisco hernandes criado del dho monasterio vecinos desta cibdad.

= Balthasar de Avila $=$ Geronimo de Valencia $=$ Xristofle
Voisin = Ante mi = Ximon Garcia Copin escribano publico.»

Por JULIA LÓPEZ CAMPUZANO

Universidad Complutense de Madrid

\title{
NUEVA APORTACIÓN DOCUMENTAL SOBRE EL SAN JUAN BAUTISTA DE MARTÍNEZ MONTAÑÉS \\ (Iglesia conventual de Santa Ana de Sevilla)
}

En el hermoso templo de carmelitas de clausura del monasterio de Santa Ana de Sevilla existe una talla de San Juan Bautista que sólo modernamente ha cobrado actualidad. La atribución de los historiadores y críticos del arte a autores varios indica un poco el misterio en el que estuvo envuelta. 
El iter de estas atribuciones, desde los Ribas, pasando por Montañés hasta Francisco de Ocampo o Alonso de Mena puede verse en una obra del profesor Hernández Díaz ${ }^{1}$. Cuando en 1985 investigamos en los fondos documentales del Monasterio de Santa Ana, topamos con un manuscrito del siglo xviII del carmelita Fernando de la Corte, titulado: Flores del Carmelo andaluz; en dicho manuscrito se traza la semblanza de la Madre Luisa de Guzmán, priora repetidas veces en el primer tercio del s. XVII del desaparecido convento sevillano de carmelitas de la Encarnación o Belén, cuya comunidad se fusionó en 1837 con la de Santa Ana y allí pasaría la estatua de S. Juan Bautista. El autor afirma que fue la M. Guzmán devotísima de San Juan Bautista y que tuvo una visión en la que contempló al Santo. como un mancebo, sentado en unos peñascos y otras circunstancias que se especifican en el relato de la misma visión. Consiguió que Montañés esculpiera una estatua, de acuerdo con sus indicaciones. Como es natural, la nota nos pareció interesante y publicamos un resumen del contenido en la veterana revista popular Escapulario del Carmen en 1987, n. 1101 con la fotografía de la talla. Al saber que el profesor Hernández Díaz tenía en estampa un amplio estudio sobre Montañés, le brindamos los datos por si podían serle de alguna utilidad y sobre pruebas de imprenta introdujo una nota (43 bis) ofreciendo las noticias que le ofrecimos y que considera fidedignas, pero no fehacientes, rechazando que estilísticamente la talla pertenezca a Montañés. Al mismo tiempo se plantea otros interrogantes, como el siguiente: "¿Será la figura del convento de Santa Ana, la encargada en el de Belén? Es una incógnita» ${ }^{2}$.

A pesar de la opinión contraria del ilustre profesor, los datos están ahí y el documento no parece dudoso. Sin salir del ámbito carmelita también Alonso Cano pintó un lienzo para el convento de Piedrahíta (Avila), a partir de la visión de una monja ${ }^{3}$.

Más recientemente M. ${ }^{\mathrm{a}}$ Luisa Fraga Iribarne ha estudiado con detenimiento el manuscrito de Fernando de la Corte y la estatua en sí y llega a la conclusión de que efectivamente se trata de una obra auténtica de Montañés y que habría que fechar en 1604, coincidiendo con el primer priorato de la M. Luisa de Guzmán. Afirma categóricamente que «Juan Martínez Montañés es, sin duda ninguna el autor del magnífico S. Juan Bautista 4.

Atentos a cualquier novedad que pudiera esclarecer más el tema, presentamos ahora copia del documento íntegro en que se apoyó el P. Fernando de la Corte -así lo creemos- y que resumió con alguna imprecisión. Se trata de un manuscrito del P. Pedro de Quesada, precisamente confesor de la M. Luisa de Guzmán. De ella pudo oír directamente el relato y puede considerarse por ahora el primer eslabón en orden a conocer pormenores sobre las circunstancias que movieron a Montañés a esculpir la preciosa imagen para el convento de Belén ${ }^{5}$ y que hoy, conforme indicamos, se venera en el de Santa Ana de la capital hispalense. Dice así el documento:

«Tambiém fue devotísima (la M. Luisa de Guzmán) del glorioso precursor San Juan Baptista y trató con las demás devotas para que en la iglesia nueva se le dedicase propio altar con su imagen de talla y retablo y ornamentos, y dexándole el cuidado y coste del retablo se encargó de todo lo demás para el mayor adormo de la misma iglesia, deseó con todo extremo que la imagen le saliese muy propia y muy perfecta que representando un hermitaño mozo, causase mucha de-

\footnotetext{
1 Hernández Díaz, José: Martínez Montañés, Sevilla, 1987, pág. 169. Notemos que ya en Ceán aparece atribuida la talla a Montañés (Juan Agustín Ceán Bermúdez: Diccionario histórico de los más ilustres profesores de las Artes en España (Madrid, 1800), Adiciones del Conde de Viñaza, 4 v. Madrid, 1889-1894, III, 93.

2 Hernández Díaz, José: Martínez Montañés, 169.

3 Velasco, B.: Un lienzo de Alonso Cano en Piedrehíta, en B.S,A.A, 46 (1980), págs. 500-504.

4 Fraga Iribarne, María Luisa: Conventos femeninos desaparecidos. Arquitectura religiosa desaparecida durante el siglo XIX en Sevilla, Sevilla, 1993, 85. Véase también la página 91.

5 Para todo lo referente a los conventos de la Encarnación o Belén véase el III volumen de nuestra obra: Historia del Carmelo español, Roma, 1994 en la segunda parte y en lo referente a los conventos femeninos (cap. VIII).
} 
voción a quantos la mirasen y estando en oración con estas ansias se trasportó en un sueño misterioso; parecióle ver al Santo como de 20 años, vestido de las pieles con el pelo adentro y sentado en un peñasco y un cordero descansando la cabeza en su rodilla izquierda a quien el Santo por el mismo lado asía con su mano, y con la derecha le estaba señalando; parecióle cosa extraordinaria i más volviendo así (sic) después del sueño, le guardó tan fixa la representación que no pudo olvidarla y aunque dando parte de ella a las demás devotas la persuadían que hiciese la imagen en la forma común, ni vino en ello, ni jamás se pudo conformar, ni sosegar.

Resistióse, en fin, de executar el sueño, persuadida que era tan extraordinario no pudiera fabricar su fantasía, y así hizo llamar luego a Juan Bautista Montanés, excelentísimo escultor, y celebrado por famoso en la ciudad y en todo el Reyno y dándole quenta muy extensa de toda su intención, y sueño le encargó en toda su conformidad la echura de la imagen que al fin se hizo de la misma suerte, que la dicha $\mathrm{M}$. avía soñado, y admirado el mismo artífice le dixo ser aquella estatua y entalladura más propia de las oraciones de quien se le pidieron que de su idea y Arte y le parecía que no acertaría a hacer otra semejante en los primores que en ella conocía, como le sucedió después queriéndole imitar al hacer otras sin atinar con igualdad a la primera hecha, pues la imagen, el retablo y ornamento se formó el altar y se adornó del todo, lo que la dicha $\mathrm{M}$. y las devotas quedaron satisfechas y han concertado todas hasta ora que varios esculptores traídos de la fama han visto y le han dado aquella imagen y queriéndola imitar han confesado que hechuras desdicen siempre mucho de ese original» 6 .

\section{Balbino Velasco}

\section{UNA NUEVA OBRA DE JUAN DE JUANES EN ATIENZA*}

En el nuevo Museo de la iglesia de San Gil de Atienza -Guadalajara-, se halla una tabla denominada Nuestra Señora de Belén en la cartela del Museo. Esta obra procede según Francisco Layna Serrano, del Hospital de San Salvador, de dicha villa (Figs. 8 y 9) ${ }^{1}$. Su tema puede considerarse también como el retrato de la Virgen. Se trata de un tipo que usa como modelo iconográfico un primitivo icono de procedencia oriental, que emula el supuesto retrato que hizo San Lucas de María 2.

La referencia más antigua que he encontrado de esta obra, es una reproducción fotográfíca anterior a la Guerra Civil, que se halla en el Archivo Fotográfico T. Camarillo, en la Biblioteca de la Diputación Provincial de Guadalajara. Lo más sorprendente es el rótulo a pie de página que allí figura, pues se juzga "presunto retrato de Isabel la Católica». Sin duda el pequeño formato de la obra, el hecho de representar el busto de una figura femenina y el remoto parecido con los nume-

${ }_{6}$ Roma, Arch. Postulación General, O. Carm., IV, 46, Vitae servorum Dei, f. 220 r ss. Se encuentra este archivo en la Vía Sforza Pallavicini 10. No hay duda que el manuscrito es obra del P. Quesada, como demuestra el P. Ismael Martínez Carretero, O. Carm. (Venerables Sevillanos, pro ms.). La coincidencia de la estatua con la descripción del P. Quesada está fuera de duda, lo que naturalmente disipa la incógnita que apunta el profesor Hernández Díaz.

* En primer lugar quiero agradecer a D. José Rogelio Buendía su ayuda en la elaboración de este artículo y sus enseñanzas como Director de mi Tesis Doctoral, así como a D. Agustín, párroco de Atienza, por las facilidades dadas en la investigación acerca de esta obra.

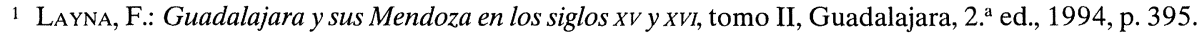

2 ALBI, J.: Joan de Joanes y su círculo artístico, tomo II, Valencia, 1979, p. 232. 